\title{
What Can Cognitive Neuroscience Do For Cultural Sociology?
}

by Omar Lizardo, ${ }^{1}$ Brandon Sepulvado, ${ }^{2}$ Dustin S. Stoltz ${ }^{3}$ and Marshall A. Taylor ${ }^{4}$

\begin{abstract}
Can cognitive neuroscience contribute to cultural sociology? We argue that it can, but to profit from such contributions requires developing coherent positions at the level of ontology and coherent epistemological views concerning interfield relations in science. In this paper, we carve out a coherent position that makes sense for cultural sociology based on Sperber's "infraindividualist" and Clark's "extended cognition" arguments. More substantively, we take on three canonical topics in cultural sociology: language, intersubjectivity, and associational links between elements, showing that the cognitive neurosciences can make conceptual and empirical contributions to the thinking of cultural sociologists in these areas. We conclude by outlining the opportunities for further development of work at the intersection of cultural sociology and the cognitive neurosciences.
\end{abstract}

Keywords: neuroscience, sociology, mirror neurons, language, embodiment, binding

${ }^{1}$ Department of Sociology, UCLA, 375 Portola Plaza, 264 Haines Hall, Los Angeles, CA 90095. Email: olizardo@soc.ucla.edu.

${ }^{2}$ Department of Sociology, University of Notre Dame, Jenkins Nanovic Hall, Notre Dame, IN 46556, Email: bsepulva@nd.edu.

${ }^{3}$ Department of Sociology, University of Notre Dame, Jenkins Nanovic Hall, Notre Dame, IN 46556, Email: dstoltz@nd.edu

${ }^{4}$ Department of Sociology, New Mexico State University, 292B Science Hall, 1290 Frenger Mall, Las Cruces, NM 88003. Email: mtaylor2@,nmsu.edu. 


\section{Can Cultural Sociology Play with Neuroscience?}

Rather than being a new issue spurred by recent theoretical (e.g. Damasio, 1994, 1999; Edelman, 1992) or technological (e.g. fMRI studies) developments, whether there can (or should) be a relationship between sociology and cognitive neuroscience has been central to the definition, demarcation, and development of the sociological project since its inception. This has been especially the case in the French, British, and American disciplinary offshoots given their more explicit commitment to naturalism vis-a-vis their German counterpart (Turner, 2007). Most of the founding figures of French and American sociology, as well as the American pragmatists and institutional economists, grappled with issues of relevance to the interface between sociology and cognitive neuroscience (Boudon, 2011; Clément, 2011).

For instance, throughout their careers, Durkheim and Mauss were interested in the relationship between the social and the cognitive (Ignatow, 2012; Lizardo, 2009b). Tarde used insights from psychology to understand how beliefs, desires, and practices propagated in society (Turner, 2007). Mead developed an account of the origins of significant symbols with a firm grounding in developmental and comparative psychology and Darwinian naturalism (Mead, 1922). Veblen grappled with the implausible psychological assumptions of neoclassical economists (Veblen, 1898). Using the concept of "the double consciousness," Du Bois (1897) famously articulated the psychological consequences of "being a problem." Pareto was interested in the affective (non-logical) influences in human action, and even Weber considered sociology to be predicated upon investigations of actors' subjective meanings and the assignment thereof to other components of action (Turner and Factor, 1994: 48-67). 
What is unique to the most recent iteration of the cognitive neuroscience/sociology conversation is that our version of this debate is being spurred by theoretical and empirical developments within a particular subfield in sociology (at least in the U.S.) under the auspices of cultural sociology or cultural theory broadly conceived (Lizardo, 2015, 2016b). Within this umbrella, a group of scholars with an explicit interest in culture and cognition studies has tackled fundamental theoretical issues in a way open to integrating neuroscientific insights (Cerulo, 2010; Ignatow, 2007; Pitts-Taylor, 2003; Vaisey, 2009).

In cognitive science, the overall trend has been towards a bridging of the divide traditionally separating psychological and neuroscientific models of cognitive phenomena (e.g., Clark, 1997; Damasio, 1999; Edelman, 1992; Thagard, 2008b). While the former make use of a mentalistic vocabulary of functions, the latter focuses on "mechanismic" or structural explanations aimed at clarifying the implementation of mental functions on the "wetware" of the brain (Foster, 2018). Today, the inter-field of cognitive neuroscience is the trading zone within which psychological research meets neuroscience; the explicit goal is the development of unified theories-in terms of underlying vocabulary, structures, and processes_-of the mind-brain, which would supplement, and at some point replace, explanation based on psychological descriptions of cognitive phenomena by grounding these in physical (i.e., realizable) neural mechanisms (Machamer and Sytsma, 2007).

This possibility of a unified cognitive neuroscience is not philosophically neutral. Cultural sociologists interested in whether there can be a productive interdisciplinary relationship here-or even considering the possibility that insights from cognitive neuroscience may inform cultural sociology—need to clarify what the relevant philosophical commitments are. As researchers interested in substantive matters, cultural sociologists may be skeptical as to what is gained from bouts of 
philosophical reflection or from making what are usually implicit commitments more explicit. From our perspective, these reflexive considerations are important because they allow us to find out which positions are compatible with a productive exchange between the two fields (Lizardo, 2014), thus making acceptance (or rejection) of the relevant ideas a principled affair. We begin by briefly reviewing the philosophical presuppositions at the basis of the idea that there can be a unified science of the psychological (cognitive) and the neural, and comment on which ontological and epistemic stances in cultural sociology we see as compatible with this project. $^{5}$

\subsection{Philosophical Stances in the Cognitive Neuroscience Project}

The primary philosophical position at the basis of the cognitive neuroscientific project is the psychoneural identity hypothesis (or mind/brain identity theory): This entails that states and processes potentially describable in psychological language are (type) identical to states and processes describable in neural language (Sperber 1987:106). Note that this goes beyond quasi-dualistic talk of pure correlations or "supervenience" relations between the neural and the mental. In this respect, physicalism is the main premise of a unified cognitive neuroscience. This position rests on the claim both mind and brain belong to the same ontological (physical) register. This view, ipso facto, entails a rejection of dualism, which is the postulation of a specifically "mental" ontological realm separate from the physical. Methodologically, this position disallows any form of explanation of mental phenomena that has to rely on "spooky" processes or entities lacking an ultimate (even if yet to be specified) grounding on physical mechanisms.

For some cultural sociologists, allegiance to physicalism may sound stronger than it is, as it may bring to mind the specter of materialism -an anti-culturalist

\footnotetext{
${ }^{5}$ For related but different attempts see Ignatow (2014) and Pitts-Taylor (2014).
} 
position which the field has fought hard to vanquish (e.g., Alexander, 1992b, 2005). Modern physicalism has little to do with the naïve forms of materialism claiming to make cultural explanation superfluous. Instead, a modern physicalist stance is perfectly compatible with a consideration of a robust role for emergent sociocultural processes in interaction with cognitive and neuroscientific mechanisms (McCauley and Bechtel, 2001).

The only commitment required by physicalism is allegiance to some form of naturalism (Sperber, 1996: 4-6). In other words, explanations in the physical, biological, cognitive, and social sciences should strive to be co-extensive and draw on the same underlying ontology (Ignatow, 2014). This stance prevents making explanatory recourse to entities and processes lacking a plausible grounding on the phenomena described in the natural sciences. In this respect, naturalism is incompatible with the claim that "the sciences of culture" or the "human sciences" deal with entities having no counterpart in the natural or physical world or that are not realizable by natural physical entities (Kaidesoja, 2013: 138-77).

One thing that naturalism and physicalism do not entail is reductionism; this is the a priori mandate to substitute talk of the properties of one set of entities (e.g. individuals) with talk about the properties of some other set entities (e.g., organizations, neighborhoods) located at a level of analysis presumed to be explanatorily privileged (e.g., the social-structural) (DiTomaso, 1982). As it relates to this paper, this would entail the erroneous claim that we must describe sociocultural properties and phenomena exclusively via the detailed properties and interactions of their "lowest" level realizers (e.g., individuals, brains, or neurons). A key roadblock for coherent dialogue along the sociology/neuroscience boundary seems to be the outdated presumption that neuroscience and related disciplines are committed to this kind of bottom-up reductionism (e.g., Duster, 2006; Sawyer, 2002: 228-29). In 
sociology, this view is likely a holdover from the "Parsons Pact" (Stoltz, 2018: 64-66) with adjacent disciplines (e.g., Parsons, 1991: 153-164). But this view is mistaken as a description of the actual commitments and scientific practices of cognitive neuroscientists (Meloni, 2014).

Instead, physicalism is compatible with both emergence and the postulation of phenomena at multiple nested levels. In neuroscience, these may include multiple brain systems acting in concert to produce a given experience or behavior, brain-behavior-environment "loops" accounting for some kinds of cognitive performance in an "extended cognition" framework (Clark, 1997). In this last respect, cognitive neuroscientists routinely make explanatory recourse to "extracranial" processes and mechanisms including the body and its effectors, other persons, artifacts and material and social "scaffoldings" provided in context for the realization and execution of complex sociocognitive tasks (Clark, 1997; Lizardo and Strand, 2010; Wood et al., 2018). These last include tasks that may require the distributed cooperation of multiple cognitive systems acting in concert (Hutchins, 1995: 225-28). In this respect, a lot of the phenomena of interest to both cognitive neuroscientists and cultural sociologists may be thought to partake of what Wilson (2004b: 989) has referred to as wide realization: Namely, the idea that a complex interplay of both brain-bound and extracranial processes contribute to generate the core sociocultural phenomena, in particular, those dependent on social interaction, material artifacts, and the intersubjective coupling of multiple agents.

\subsection{The Relevance of Cognitive Neuroscience for Cultural Sociology}

\subsubsection{Interfield Dependencies}

We allude to these philosophical issues as a way to signal that any answer to whether cognitive neuroscience is relevant for cultural sociology entails taking 
coherent positions at the level of ontology and concerning the proper set of relations between different scientific fields (Thagard, 2008a: 7-8). This requirement harks back to fundamental issues regarding the relationship between sociology and adjacent disciplines such as psychology, issues that have plagued the field since its inception (Durkheim, 1982; Parsons, 1937).

For instance, any consideration of the relevance of cognitive neuroscience for cultural sociology would be moot if the analyst holds the "autonomist" position that sociology is independent from any "lower-level" analysis corresponding to individuals, persons, interaction, or minds (Black, 2000). Instead, for the conversation to begin, the analyst must presuppose interdependence (or intersection) between cultural sociology and cognitive neuroscience (Cerulo, 2010; Patterson, 2014). Whether this interdependence is asymmetrical (with insights flowing from one discipline to the other) or symmetrical (with sociological work informing research on cognition and vice versa) is an important consideration but not as relevant as the first.

Our view is research and theory in cultural sociology depends on the results from cognitive neuroscience, but only in a moderately strong way. In principle (and in practice) it is possible to be an expert in cultural sociology while paying no regard to fundamental principles regarding how cognitive phenomena are realized in the brain. However, our contention is that even when claiming to research or theorize at a purely cultural level of analysis, scholars cannot get very far without making minimal assumptions about how human agents end up having ideas about the world or developing categories, memories, habits, frames, narratives, or worldviews (Bloch, 2012; DiMaggio, 1997; Strauss and Quinn, 1997). If not overtly invited, cognitive assumptions will always sneak in through the back door (Foster, 2018). Where even minimal reference to cognitive processes and constructs is pervasive in cultural sociology, then there is the possibility for a link to cognitive-neuroscientific theory. 


\subsubsection{Novel Conceptual Distinctions}

Whether or not this link we exploit is the analyst's choice, our only point is that better cultural theory would result if the underlying cognitive-neuroscientific assumptions made by the theory are both explicit and are the ones that are most empirically plausible or have received the most support (Patterson, 2014). Besides, by delving into the relevant neuroscientific literature, cultural analysts may also come across new constructs, processes, assumptions, and mechanisms they would not have thought of from the armchair (Summers-Effler, 2004).

For instance, while philosophers had made distinctions between "knowing how" and "knowing that" base on conceptual analysis (e.g. Ryle, 2002 [1949]: 25-61), it took research in the psychology and neurobiology of memory to discover that the latter category further segmented into semantic, episodic forms of knowledge, and that "how" (procedural) memory was actually a subcategory of a more inclusive form (e.g., including priming, and conditioning memory) called "nondeclarative" (Squire, 2004). Thus, what had been treated as a unitary "natural kind" in the conceptual analysis tradition turned out to be a set of analytically distinct, causally heterogeneous set of entities and processes (Michaelian, 2011). Cognitive Social Scientists, in their turn, have used insights from this new strand of research on memory systems to shed light on and theorize the statics and dynamics of such prototypical cultural phenomena as religious movements, ritual, and cults (Whitehouse, 2004).

In the same way, projectivity, or the ability of persons to "travel forward" in time into the future and generate plans, postulate hypothetical future scenarios, and simulate alternative courses of action has been central to theorizing in cultural sociology since Schutz (Emirbayer and Mische, 1998; Tavory and Eliasoph, 2013). What theorists could not have predicted from the armchair is that episodic memory (travel backward in our life timeline) and projectivity (travel forward) are actually two 
subcategories of a more general "hypothetical imagining" ability subserved by the same neural circuits and sharing fundamental properties inclusive of those that allow for counterfactual reasoning more generally; if one is disrupted, so are the other ones (Suddendorf, 2013). Thus, cognitive neuroscience suggests sociologists should deal with what otherwise would have been treated as "analytically distinct" processes requiring separate bodies of theory, using a single conceptual language.

Several other concepts in cultural theory, including "action," "symbol," "imagination" and even the notion of "category" may be subject to a radical rethinking due to discoveries in the cognitive neurosciences (Blouw et al. 2015). We believe a cognitive neuroscientifically informed cultural theory is thus better and potentially more insightful and generative than one that makes unstated assumptions, or whose assumptions are wrong, outdated, or misleading.

\subsubsection{Settling "Meta-Theoretical" Debates: Infra-individualism}

Another way cultural sociology can benefit from a deep engagement with cognitive neuroscience is that thorny "meta-theoretical" debates in cultural sociology can be replaced by more theoretically productive substantive debates capable of empirical adjudication or even conceptual transcendence (e.g., Turner, 2001). For instance, during the 1980s and 1990s, a "fundamental" problem in social theory was that of the "micro-macro" link (Alexander et al., 1987). The issue concerned the relationship between levels of description with the lower level usually being thought of as composed of unitary individuals. As analysts have thought seriously about the link between cognitive neuroscience and social science (including cultural sociology), it has become clear that the issue is no longer one separating individualism and holism. Instead, as Sperber (1997: 123) has cogently argued, the main issue is whether the black box of the individual shall be cracked open so that processes that occur below the level of the individual (e.g., in terms of phenomenological time-scale) are 
admitted as necessary for the job of explanation.

Sperber-style "infra-individual" processes are now commonly accepted in cognitive psychology and neuroscience. Only recently have cultural analysts thought about how they fit into traditional social science theory and research (Shepherd, 2011; Srivastava and Banaji, 2011; Vaisey, 2009). For instance, when presented (subliminally) with pictures of faces with males of dark skin, and then asked to add a letter to complete the sequence "GU_" so it forms a word, undergraduate U.S. subjects are statistically more likely to select "N" than "M." The infra-individual process explaining this effect is that of "spreading activation" from representations of black males to representations of weapons as mediated by stereotypical associations between black males and violence in the U.S. (Kunda and Thagard, 1996: 285). "Spreading activation" is a psychological description of a cognitive process, but one that can be given a mechanismic implementation in the form of interconnected neural systems tuned by experience (Lakoff, 2009; Thagard, 2008a).

Infra-individual processes are also relevant to a variety of core phenomena studied by sociologists and may themselves be modulated via top-down constraints imposed by contexts and institutions (Lizardo and Strand, 2010; Shepherd, 2011; Stoltz and Taylor, 2017; Wood et al., 2018). For instance, cultural sociologists usually pitch such commonplace constructs as "habitus" at the infra-individual level (Bourdieu, 1990; Mukerji, 2014); and qualify them as having both cognitive, and presumably neurocognitive, foundations (Downey, 2014; Lizardo, 2009a; Potter et al., 2013). In this respect, infra-individualism emerges as an appealing option in that, by "dissolving" the individual, unlocks the potential to theorize the "collective-social" at a level below the person;as suspected by Levi-Strauss (1966), the infra-individual level may represent the royal road to the collective unconscious that Durkheim was after.

In what follows, we use three case studies to show the theoretical benefits of 
taking an infra-individualist, extended-cognition approach to cultural phenomena grounded in cognitive neuroscience.

\subsubsection{Three Case Studies}

First, we critically consider the propriety of the conceptualization of linguistic symbols as "amodal" carriers of meaning motivating the metaphor of culture-as-code. We present an alternative "modal" conceptualization of linguistic symbols and categorization, built from neurally motivated understandings of cognition as grounded in the body. This approach allows us to propose a new way to think of the link between language, culture and collective categories (Ignatow, 2007).

Second, we review recent advances in the study of "mirror neurons" providing a neurocognitive motivation for a rethinking of the fundamental basis of intersubjectivity (Bloch, 2015). We show that there is no need to assume a deliberate, language-mediated, conscious exchange based on reflective meanings as the primary route to intersubjective agreement as is typical in the social phenomenology tradition that has been influential in cultural sociology (Heiskala, 2011). These insights have both substantive and methodological implications.

Finally, we tie together two strands of inquiry, one from neuroscience and one from cultural sociology, dealing with the fundamental question of how discrete elements become associated as to be considered a single element in experience. This mechanism underlies such disparate phenomena as how the cognitive meaning of symbols come to be "bound" to the external markers that serve as their "signifiers" (de Saussure, 1964; Peirce, 1974). This mechanism also helps to account for how certain social categories come to be linked to socially relevant affective and relational dimensions expressive of moral (good/bad) or hierarchical (powerful/not powerful) status (Douglas, 2002). The resulting analysis provides a novel and useful take on classical issues. 


\section{Opening The Linguistic Black Box}

Cultural sociologists often rely on a "linguistic" metaphor to conceive of how cultural systems can be systematically structured while allowing for individual creativity in practice (Biernacki, 2000; Sewell, 2005). Some go further and see external linguistic symbols as a model for cultural processes in general, suggesting social action should be read as text (Alexander, 2003: 21-22; Ricoeur, 1973). In this respect, these analysts draw from a venerated tradition in cultural theory. For instance, both Parsons and Geertz transitioned from describing culture as a "system" toward a linguistic metaphor in the late 1960s (Lizardo, 2016b). Other analysts consider language as a primary means of (cognitively) "constructing" social reality (e.g., Berger and Luckmann, 1966). This conceptualization is common to classical functionalist, phenomenological, and interpretivist schools of cultural theory (Lizardo, 2016a). Recent work in cognitive neuroscience, however, suggests that we may have to rethink the dominant version of the linguistic metaphor as well as the role of language in cognition in fundamental ways.

Drawing on Saussure and his (mis)interpreters, the classical model holds that the relationship between a linguistic symbol (signifier) and that which is symbolized (signified) is of an arbitrary nature. At the extreme, the relationship between the signifier and signified is presumed to be entirely incidental to the internal organization of the system via sequential and substitutive relations between otherwise meaningless symbols. This tendency comes out most clearly in Giddens (1979), who draws inspiration from the distinction between langue and parole to conceptualize the distinction between the structural and practical "moments" of social systems (respectively). Meaning and signification are generated in the structure of concatenation, substitution, and (usually binary) opposition encoded in langue. 
Following Ignatow (2007) we refer to this as an "amodal" conception of how meaning is produced in language and, by extension, culture (see also Shore, 1996: 356-58). This neo-Saussurean model of language is "amodal" because the theory presumes sensory inputs from the "modalities" (bodily senses) are not relevant for the constitution of linguistic meaning. Nor is the acquisition, storing, and implementation of linguistic (or other cultural) knowledge, in specifiable neural structures of relevance to the theory. We argue both the description of language as a disembodied sign system structured exclusively by segmental and contrastive oppositions and the corollary position that the realization of linguistic knowledge in body and brain is not consequential for the operation of language, are not consistent with how these phenomena are characterized in contemporary neuroscience. Therefore the metaphorical extension of this linguistic analogy to other aspects of social life, such as culture, action, or "structure" may be equally problematic.

\subsection{The Embodiment of Language}

Recent advances in cognitive neuroscience suggest that linguistic and cultural knowledge is "embodied" in a fundamental sense (Gallese and Lakoff, 2005; Johnson and Lakoff, 2002; Kovecses, 2006; Lakoff and Johnson, 1999). In this regard, they are contributing to a long tradition in anthropology, phenomenology, and even sociology, which stresses the necessarily_ "always, already"—embodied base of both pragmatic and symbolic processes (Bourdieu, 1990; Cassirer, 1957: 205-261; Crossley, 1995; Engman and Cranford, 2016; Hertz, 2013 [1960]; Merleau-Ponty, 1962, 1968; Schwartz, 1981; Wacquant, 2004)

In this modal conception, words and phrases serve as contextual pointers to concepts, but they are not themselves concepts. Rather, concepts are dynamically built-up from elements recruited from the modal systems of perception, action, and 
emotion used to interact with the world (Evans, 2009; Gallese and Lakoff, 2005). Concepts and categories, rather than being singular "tokens," are best understood as made up of a panoply of context-sensitive infra-individual processes recruited for specific typification tasks in context (Barsalou, 2003b). A key discovery here is the structural overlap between systems used for "online" action (including speaking) and systems used for "offline" thinking at the neural level. Persons rely on the same neural structures that they use to do things to imagine things; imagining is "grounded" in the doing (Anderson, 2014; Barsalou, 2003b; Glenberg and Kaschak, 2002; Johnson and Lakoff, 2002; Lakoff, 2009).

The implications of the modal conception of linguistic meaning for cultural sociology are important. Acts of linguistic categorization are not just products of arbitrary convention, precariously maintained by social consensus. Instead, cultural categories are grounded in non-arbitrary resources, based on people's ability to extract the correlational structure of experience from continued, pragmatic, embodied engagement with the material affordances of the environment (Bloch, 2012; Bourdieu, 1990; Wood et al., 2018). We illustrate the implications of this overall claim in two domains: (1) how people represent and categorize objects, and (2) how people recruit modal representations obtained from concrete experiences to reason metaphorically about abstract concepts.

In a review of functional neuroimaging research on object perception, Martin (2007) finds perceived properties of objects are stored in sensorimotor systems active during the time of exposure. During conversations, when objects are referenced but not present, the same sensorimotor traces are activated to "represent" these objects for both speaker and recipient (see also Lakoff, 2009). This tenet is contrary to amodal theories of language, which presume that "we can begin to speak of language only when vocal expressions have become capable of detachment from the 
immediate "here and now" (Berger and Luckmann, 1966: 51). Instead, comprehension of words happens via similar neural mechanisms as those involved in the comprehension and execution of other "indexical" signifying actions such as gestures. This postulate is also true for "speech sound" as an object, as there is evidence the act of auditory comprehension incorporates the same "motor representations of the articulatory gestures that would be necessary to produce these speech sounds" (Willems and Hagoort, 2007: 279).

These findings are taken one step further with the motor theory of speech perception: not only does speech perception recruit motor systems, but this is a requisite for speech comprehension. Because of this integration of language and action, researchers find sign languages recruit cortical structures in deaf signers that are functionally equivalent to those that subserve spoken language in hearing persons (Willems and Hagoort, 2007: 286). The finding that variability at the linguistic surface is grounded in shared semantic concepts holds in fMRI studies of bilingual individuals. For instance, one study concludes that "it is possible to identify which word [the bilingual participants] are thinking about using the semantic neural representation elicited by words in either language" (Buchweitz et al., 2012: 286; see also De Grauwe et al., 2014). Therefore it is misleading for sociologists to speak of language as a disembodied, abstract structure, or of different languages as constructing entirely discrete worlds based on pure relations of signification (e.g. Shotter, 1993; Wierzbicka, 1996).

Cultural theorists may grant that work on the neural embodiment of language may be restricted to the acquisition and use of concrete conceptual knowledge, but claim that it cannot account for how persons engage the world of more "abstract" concepts. That is, we see abstractions as more properly "cultural" with their meaning fixed by arbitrary convention (Parsons, 1938). Contrary to this view, the neural 
embodiment thesis is a general account of how people process the meanings of all concepts: both "experience-near" and "experience distant” (Barsalou, 2003a; Lakoff, 2009). The key is to outline an infra-individual mechanism, capable of neurocognitive implementation, allowing persons to conceptualize abstractions-i.e., those not directly grounded in imminent experience-using embodied resources (Barsalou, 2016).

This mechanism is analogical transfer, especially as instantiated in conceptual metaphors (Lakoff, 1993, 2009). Via this mechanism, resources can be recruited from an experience-near (concrete) source-domain to conceptualize the structure of an experience-distant (abstract) target domain. This mechanism, foundational to first-generation work on conceptual metaphor (Gentner, 1983; Lakoff and Johnson, 1980) and Schwartz's exemplary sociological work on vertical classification (Hertz, 2013 [1960]; Lukes, 2003; Schwartz, 1981), is naturally realizable in realistic neural architectures, yielding the contemporary "neural theory of metaphor" (Lakoff, 2009).

Take, for example, professional success, which people often associate with verticality metaphors such as "moving [on] up," "climbing the corporate ladder," "getting a raise," or "coming out on top." Success may also be associated with forward movement along a path, "getting ahead," "surpassing," "advancing," "going the distance," or "leaving everyone else behind." Often success is not without difficulty, which tends to be understood as obstacles along the path or ladder that must be overcome, however, certain people may "run into a barrier," or certain groups may encounter a "glass ceiling," stopping their forward progress (see Lakoff and Johnson, 1999: 52-53). At the level of lexical choices there is a variety of words and phrases, but when reduced to the embodied concepts underlying each, we can see an implicit (and coherent) cultural model of professional success/failure. As this domain is less experience-near

\footnotetext{
${ }^{6}$ For work on lateral classification see Hertz (2013 [1960]) and Lukes (2003).
} 
than, say, walking in a field or up a hill, it is conceptualized by analogy to bodies moving along more or less difficult terrain. Conceptualizing abstract domains using motion metaphors re-activates many of the same sensorimotor schemas that would be used if one was moving (Casasanto and Boroditsky, 2008; Sakreida et al., 2013; Wood et al., 2018), providing intuitive internal coherence to the model (Lakoff, 2009), and explaining its "catchiness" (Sperber, 1996: 57-67).

The modal conception of linguistic meaning and conceptualization just sketched also suggests cultural sociologists should handle neo-Saussurean "meaning contrastive" notions with care and a little more skepticism (Bloch, 2012). Perhaps the most influential neo-Saussurean concept in American cultural sociology is that of the "binary code." Alexander and Smith, for instance, claim that "binary opposition" is "a precondition of discourse" (2001: 143, emphasis added) and go even further to argue "that culture [is] a classification system consisting of binary oppositions" (2001: 145). With "political culture," this binary structure establishes "the categories of sacred and profane in civic life" (Alexander, 1992a: 302).

Although binaries are pervasive in social life, their power to "structure" may not be necessarily due to their foundational status in a disembodied sign system. Rather, we can conceive binaries from a modal embodiment perspective, as emerging from the sensorimotor and proprioceptive experience of our "binary" bodies as first noted in classic work in embodied phenomenology (e.g., Todes, 2001)_back and front, up and down, left and right_-which carry their own unique, and often asymmetrical, entailments, as also recognized by Durkheim, Mauss, and their students (Hertz, 2013; Lukes, 2003; Schwartz, 1981). The enablements and constraints of binary discourse are thus grounded in the meaning-making potential of the body (Dreyfus and Spinosa, 1999) linking action, conceptualization, and culture at an infra-individual level (Lakoff, 2009). 


\section{Neural Embodiment and the Problem of Intersubjectivity}

"Every day" reality is taken-for-granted as shared; it is an "intersubjective" world (Garfinkel, 1967: 36). Intersubjectivity maintains a hallowed place in cultural sociology as it would be hard to imagine social organization at any level without some attunement of thought and feeling between two or more individuals. ${ }^{7}$ Beginning with Berger and Luckmann (1966), and the dividends paid by Schutz's phenomenological sociology, the "problem" of intersubjectivity is the "enigma of how man [sic] can understand his fellow man [sic]" (Schutz, 1962: 179; see also Russell, 1905: 480). It is interesting, however, precisely because it is only an enigma for those who have time and motivation to think about it. It takes a "special motive" to make our intersubjective reality problematic (Garfinkel, 1967: 37), and therefore it happens rarely. Presumably, we cannot have direct experience of another's subjectivity, and so, since Schutz, sociologists have attempted to explain the ease with which ego can seem to know what alter is thinking.

The phenomenological solution involves positing that persons rely on a set of default assumptions presuming the existence of intersubjective agreement before examining whether such evidence exists (Stoltz and Lizardo, 2018). When such assumptions are violated, the situation requires more or less deliberate repair. People learn the default assumptions via prior experience; shared understandings are built "by people testing and checking each other's talk, by them questioning and challenging it, reformulating and elaborating it" (Shotter, 1993:1; see Iacoboni 2009:666 for a critique).

This solution, which we might call deliberative, is valid sometimes, but it is unlikely to represent the fundamental way in which persons relate to one another at

\footnotetext{
${ }^{7}$ The very act of thinking about this possibility necessitates bracketing knowledge of human (and primate more generally) evolution (see for example (Kaufmann and Cordonier, 2011)).
} 
an intersubjective level (Gallese and Metzinger, 2003). One problem is that the deliberative solution overlooks what Maurice Bloch calls the "indeterminacy concerning the physical boundaries of individuals" (2015: 5; see also Wilson, 2004a). It glosses over an important question (where do the selves of persons begin and end?), one which is especially problematic outside of Western cultural coordinates.

If experience does not dictate the "natural" boundaries of other persons, and if individuals do not rely on linguistically mediated assumptions and principles to deal with this demarcation issue, then is this massive empirical underdetermination problem solved? Recent work in the cognitive neuroscience of social cognition may hold the key to an answer. We refer in particular to the discovery of the "mirror neuron" system in humans and other primates (Gallese, 1998; Iacoboni, 2009; Lakoff, 2009; Lizardo, 2007). This neural system instantiates a mechanism capable of accounting for the routine ability of persons to "read" minds and to comprehend the meaning of actions at a direct (non-symbolic) level (Gallese and Metzinger, 2003: 381).

As Bloch (2015) argues, just as humans "go in and out of" each other's bodies in sex and birth, they interpenetrate each other's minds. This feat is made possible by a shared neural substrate that becomes active whenever a person performs an action and perceives the execution of the same action by conspecifics (Iacoboni, 2009; Rizzolatti et al., 1988). As Ferrari and Gallese (2007:73) note, “our nervous system has been constructed in such a way it enables us to capture others' living experiences just by watching them." Thus, besides providing a non-deliberative, infraindividual solution to the problem of intersubjectivity, one aligned with the actor's phenomenological experience of the pervasive ease of mutual understanding. As such, the infraindividual mirror neuron mechanism has fruitful implications for cultural sociology. Here we briefly consider two: role-taking and solidarity, and thick 
description.

\subsection{Role-Taking and Solidarity}

As Franks notes, in Mead's classic theory of role-taking the "actor incorporates the imagined response of the other into his emerging behavior" (2013: 28). For Mead, the medium of this incorporation is the "significant symbol." The mirror neuron mechanism reveals the embodied foundations of intersubjectivity, including the neural-representation of selves, intentions, and goals at a motor level (Gallese and Metzinger, 2003), thus overcoming the residual linguistic bias in Mead's conceptualization of role-taking. In this account, inferences as to the other's state of mind can be automatically simulated from the perceptual and sensorimotor schemas gained from mundane experience in the world (Lakoff, 2009; Wood et al., 2018). This implies persons mutually coordinate at an infraindividual level without the mediation of significant symbols (linguistic or otherwise), a phenomenon with a long history of examination in sociology and psychology (going by the name of "imitation" in Tarde) and "entrainment" in contemporary interactionism (Summers-Effler et al., 2014).

For instance, Chartrand and Bargh (1999; see also Lakin et al., 2003) refer to the automatic tendency to adopt the postures, gestures, and mannerisms of interaction partners the "chameleon effect" (cf. Collins, 2004 on 'entrainment'; and see Summers-Effler et al., 2014 for an application of the neural-embodiment approach to ethnography). Whether persons can "mirror" one another, and by implication share the same "lifeworld" as the other person, may thus depend on whether there is a common experiential history between them. The extent to which we can observe mirroring thus becomes an empirical question and may be tied to traditional concerns with socio-cultural processes generating and perpetuating "symbolic boundaries" between groups (Lamont et al., 2008) and reinforcing status hierarchies (Ridgeway, 1991). For instance, Cheng and Chartrand (2003) find 
participants more likely to mimic another if they believed them to be a "peer" rather than a "superior" (see also Molnar-Szakacs et al., 2007 for cross-national comparisons of gestures).

This dovetails rather seamlessly to a key observation from sociology and anthropology regarding the importance of ritual in producing solidarity. Certainly, Durkheim's Elementary Forms is central to this tradition. Specifically, he observes otherwise dispersed populations "com[ing] together, concentrating itself at specified places for a period...because a collective emotion cannot be expressed collectively without some order that permits harmony and unison of movement, [their] gestures and cries tend to fall into rhythm and regularity" (quoted in Bellah 2005: 183-210). Similar observations are made by Macneil in Keeping Together in Time, as it relates to "muscular bonding," in which militaries, religions, and social movements exploit the emotional consequences of moving together in time such that individuals experience "boundary loss" or they feel as if they are one (1995:8). More recently, Summers-Effler (2010), building upon Collins' interaction rituals, explores why social movements fail or succeed. She argues that what we tend to think of as stable groups should actually be conceived as "rhythmic patterns of organization." The mirror system provides the neural mechanism by which moving together in rhythms lays the pre-linguistic foundations of solidarity.

\subsection{Thick Description}

Many sociologists are already sensitized to the diversity of embodied skill and capacity (Engman and Cranford, 2016; Mellor and Shilling, 2010; Pitts-Taylor, 2015) and can contribute to the growing body of research on the neuroscience of social cognition. While this opens several rich possibilities for cultural analysis, we should pursue this project with caution. Incongruences in mirroring are likely to be of social significance, but it is unlikely that we can find a limiting case of no mirroring between 
persons at all; only gradations in the degree of mirroring. In this respect, the existence of the mirror neuron mechanism rules out the possibility of persons occupying completely unbridgeable worlds of meaning and experience as an empirical absurdity (Gallese and Metzinger, 2003), thus deflating a popular argument against the unity of the natural and social sciences (e.g. Winch, 2012). Even people with drastically different life experiences, languages, and "cultures" (in the folk sense) are still likely to share a great deal of practical experiences by dint of sharing a common physical world of objects and structured experiences afforded by the body.

In this respect, the operation of the mirror neuron mechanism also has concrete methodological implications for cultural analysis. We can draw a relevant example from Geertz's extensive discussion (1973: 6-7) of Gilbert Ryle's (1971) example of boys winking in his essay on "thick description." Seen in the above light, knowing the difference between blinking and winking (or a parody of the wink), may be possible even in the absence of a shared "public code" that settles the meaning of the action (Mukerji, 2014). Cultural sociologists may have to countenance the possibility that the embodied simulation mechanism associating specific bodily actions with action-intentions at a nonlinguistic level may fix the "meaning" of certain actions among persons. This approach also suggests that learning the "public code" of winking may not be a sufficient condition for noticing how the various fine-grained (and provisional) distinctions between, for instance, a sincere wink and a parody of a wink in situ (Lempert, 2014).

The implication is that so-called "thick description" may only be achieved by a deployment (whether intuitive or reflexively) of the techniques that have recently been codified as "carnal sociology" (Mears, 2014; Pitts-Taylor, 2015; Wacquant, 2004). Becker and Geer (1957: 28), comparing the virtues of participant observation to that of the interview, suggest that a problem for the latter is the degree to which 
"the researcher has observed the behavior he [sic] is talking about." A virtue of ethnography that Geertz, Becker, Geer, and many others omit is that "participant observation" is more than just being present to "objectively" record activities on paper as they unfold (in fact, as even the well-honed human mind can only focus on so much, a great deal of potentially relevant information in the situation will evade conscious perception). Rather, the significance of the technique is that, as the analyst engages in the same activities of the participants, recording the practical requirements of those activities in the body of the analyst (Mears, 2014). The participant observer can grow increasingly confident in their automatic inferences as to the meaning of an action, phrase, or event in that context as they become enculturated into the local context (Pagis, 2010).

\section{Making One Out of Many: The Binding Problem}

Binding is the infra-individual processes via which two initially separate cognitive (or affective) elements are "fused" into a single representation. This operation results in perceptual, cognitive, and affective constructs endowed with unitary experiential qualities. From the perspective of cultural sociology, binding may, therefore, be one of the most fundamental neurocognitive processes (Taylor et al., 2019).

For instance, binding is involved in the generation of implicit (or explicit) associations between previously unrelated cultural elements (Goldberg and Stein, 2017; Shepherd, 2011); the link between cognitive representations of objects, events, properties, and specific affective values (e.g. linking "men" and "powerful" or "success" and "good" (Robinson et al., 2006)); the integration of singular or concrete representations (e.g. "woman" and "parent") to generate higher level concepts pertaining to roles and identities ("mother") which are then bound to particular 
occupants or "fillers" (Bloch, 2008); and even the linkage between the material pole of symbols (signifiers) and their cognitive meanings (signifieds). The capacity of humans to bind unrelated elements into single constructs may lie behind the bewildering capacity for cultural variability and idiosyncrasy that is the traditional impetus for cultural analysis (Sewell, 2005).

Most cultural sociologists help themselves to concepts playing the role of binding. The most famous, as already alluded, is the Saussurean idea of the permanent link (e.g., like two sides of a sheet of paper) between the acoustic "image" of the linguistic symbol (signifier) and the concept it points to (signified). These formulations, while evocative, remain imprecise. In this respect, considering binding as an infraindividual process opens lines engagement with the cognitive neurosciences that can link up to work in cultural sociology emphasizing the discursive side of "social construction" (e.g., focusing on how linguistically articulated symbols come to be linked in historically specific ways).

A focus on different forms of binding sensitizes cultural sociologists to the experiential dimension of cultural phenomena (Johnson, 2012). For example, how is it that in the United States, a good proportion of the population come to experience dangerous black men as a unified object, one that can be directive of behavior at an implicit level, such as crossing the street (Steele, 2011)? How can the Eucharist be immediately experienced as sacred even in the absence of discursive "belief" (Sørensen, 2007)? What is it about the motorbike that provides a pathway to "authenticity" among working-class Britons (Willis, 1978)? Recent work modelling the neurocognitive realization of binding mechanisms can shed light on some of these issues, while allowing cultural analysts to make finer-grained distinctions between different ways in which "binding" manifests itself as a cultural phenomenon and the contextual conditions that facilitate it. 
Most work on the "Neural Binding Problem" (Feldman, 2013) in neuroscience focuses on lower-level forms of unification, such as addressing mainly issues of perceptual binding in visual fields and figure-ground distinctions (von der Malsburg, 1994), and the neurophenomenological substrates of unity in consciousness (Cleeremans, 2003). Higher level forms of binding (e.g., conceptual, symbolic, or affective) are treated under the heading of "variable binding" (Browne and Sun, 1999). Variable binding refers to the processes by which "symbols are designated to represent entities" (Browne and Sun, 1999: 189). Our focus is on this last given its more direct relevance for core work in cultural sociology (Taylor et al., 2019).

We highlight one such process here: convolution and the development of semantic pointers (Thagard and Stewart, 2011). Convolution is the infra-individual process by which two or more already-learned representations, encoded in the pattern of firing of populations of neurons, bind to form a unique representation that is irreducible to its component parts. With convolution, binding occurs not when neurons fire together, but when pre-learned patterns, sometimes recruiting entire neural subpopulations, come to be temporally synchronized (Thagard and Stewart, 2011). ${ }^{8}$ Convolution is a useful mechanism for theorizing cultural phenomena because it plays the role of a "compression operation" (Blouw et al., 2015: 6)—that is, a mechanism by which people mesh diverse lower order cultural elements (e.g., perceptual, experiential, symbolic, and/or affective) into higher order representations that can be manipulated, used, and experienced as a unity. These composite representations_or "semantic pointers" (Eliasmith, 2013)—are made possible by variable binding processes. They may also be a good candidate for the emergent

\footnotetext{
${ }^{8}$ This phenomenon is analogous to what cognitive neuroscientists refer to as "temporal synchrony" (Feldman, 2013; Shastri, 1996), or the idea that analysts are more likely to observe binding when the neurons are activated concurrently.
} 
mental entity that Durkheim (1974) once referred to as "collective representations."

While basic perceptual binding allows us to pair together color and form percepts to form on-the-fly distinctions between, say, green apples and red oranges (van der Velde and de Kamps, 2006), a semantic pointer might include this information and more contextual information like "green apples are sour" or "red oranges are blood oranges." This process is recursive: semantic pointers can themselves be bound via convolution to form even higher level representations, allowing for otherwise different semantic pointers to come together into a "supra" pointer and stored in long-term memory. Compressing experiential and cultural information into semantic pointers, however, comes at a cost: since they exist as summaries, they can be decomposed to only approximate their parts—not fully reconstitute them (Blouw et al., 2015).

There are two implications of isolating infra-individual binding processes for cultural sociology. First, since convolution gives rise to novel (emergent) representations, two or more cultural elements that bind in time and space need not be bound at all times (Taylor et al., 2019; Quilley et al., 2013). This is the difference between what Lakoff (2009) refers to as obligatory (characteristic of perceptual bindings such as an apple's shape and color specifications) and nonce bindings (put together on the fly and determined by characteristics of context). This approach suggests that some lines of research in cultural sociology may be on the right track in conceptualizing culture as an individual's repertoire (i.e., procedural memory) for forming coherent representations as situations arise rather than storing them ready-made (Lizardo and Strand, 2010; Martin, 2010), and thinking of cultural change as the diffusion of metaphors, objects, and dispositions reflecting novel bindings between previously unassociated concepts and practices (Goldberg and Stein, 2017). Second, the fusing of two or more cultural elements need not (and, in everyday life, 
usually is not) linguistically mediated. To be sure, Durkheimian symbol sacralization processes are central instances of variable binding — such as when material objects, events, and historical figures become core pointers to emotionally shared collective discourses and memories in a community (Armstrong and Crage, 2006; Wagner-Pacifici and Schwartz, 1991), but are not necessarily the most empirically common instance.

Binding processes operating over linguistic symbols cannot be the most common form given the inefficiency of such symbols to carry rich experiential meaning directly (Evans, 2009; Glenberg, 1997). As Ignatow notes (2015: 6), language is a prompt to simulate in acts of meaning construction rather than directly encode pre-packaged meanings in most everyday instances. This thesis implies that language functions mainly as a vocal or written transformation of an otherwise non-linguistic bind (Bloch, 1991). For instance, this latter may include iconic and imagistic ways of performing "power" in the everyday material arrangements, e.g., linking power and position in the vertical dimension (Schubert, 2005; Schwartz, 1981). In this way, the binding of non-arbitrary meanings to discursive, relational, and performative elements may be a crucial part of a multilevel mechanism contributing to the emergence and reproduction of power as a social phenomenon (Reed, 2013).

\section{Discussion}

Having offered concrete examples of how insights from cognitive neuroscience may inform cultural analysis, we are now in a position to specify what we see as the most coherent stance for sociologists interested in productive dialogue between cultural sociology and cognitive neuroscience. Any fruitful influence of cognitive neuroscience in cultural sociology provides naturalistic foundations, which, in this case, entails admitting that the processes and mechanisms described in 
cognitive neuroscience are constitutive of the social actor (Turner, 2007).

As we argued at the outset, this does not entail reductionism, as this position is perfectly compatible with an ontology of emergent systems (Wan, 2011), "wide realization" (Wilson, 2004b), and "explanatory pluralism" across different domains (McCauley and Bechtel, 2001). This last point relates closely to the explanatory unit of analysis. If a cultural sociologist is to embrace cognitive neuroscience, then methodological individualism, with individuals as rock-bottom black boxes and the tools of commonsensical belief-desire psychology, and literary narrative as the main way to "interpret" action, is not a coherent strategy (Strand and Lizardo, 2015). We argued instead that infra-individualism is a more coherent strategy. If we are to turn to infra-individual mechanisms, then this raises the question of physicalism, and, as before, it is not clear that a uniquely determined position for the cultural sociologist exists. Our point is that asking cultural sociologists to embrace a minimalist form of physicalism compatible with naturalism (and no "spooky" entities) is not asking for much. ${ }^{9}$

An instructive example in this respect is that of psychoanalysis. Once central to many strands of social theory, including structural functionalism, critical theory, and their immediate offshots (Elliott 2019; Marcuse 2012; Parsons 1964; Smelser 1999), psychoanalysis stands out as the most ambitious strands of 20th century social theory, especially in its attempt to link "unconscious" processes to societal outcomes. In this respect, there is a non-trivial relationship between the Freudian penchant to go "below consciousness" and the infra-individualist call to go one level "below" the individual. However, we argue the parallel is stronger than this. While psychoanalysis became influential in social theory and the humanities more general in the form of a purely mentalistic "meta-psychology" couched in concepts and mechanisms (e.g.,

\footnotetext{
9 Only cognitive neuroscientists must embrace strong versions of the psychoneural identity theory, and this is mostly for methodological reasons.
} 
ego, id, repression) seemingly unmoored from underlying neural processes and their realizers, this was not the way that Freud initially conceived of it. Instead, the earliest version of psychoanalysis, as laid out in the "Project for a Scientific Psychology" (Freud 1966) was in fact in the form of an (armchair) neuroscience, one that was surprisingly accurate for its time (Pribram and Gill 1976). In that respect, we can see the infra-individualist project as both an update and a reset of the original psychoanalytic impetus to deconstruct the individual as a unitary entity in social science.

An additional advantage of the infra-individualist emphasis in contemporary cognitive theory is that it makes hash of the 19th-century debate (revived in the post-functionalist period under the heading of the micro-macro debate) regarding the direction of sociological causality. While the distinction between individual affecting society or society influencing the individual, as in the "social structure and personality" tradition, describes early efforts to incorporate cognition into social theory, the state of current cognitive-sociological and neuroscientific research implies that the distinction was misguided from the outset and was a misleading basis from which to engage in disciplinary boundary work.

As Geertz (1973) first noted, humans evolved such that developing functioning neural architectures requires cultural supplementation (Lakoff, 2009; Tomasello, 1999). The specification of how mechanisms at the cognitive and neural levels may inform theorizing in cultural analysis, such as the ones mentioned earlier, confound simplistic binaries between "inside the head" and "outside the head," which cultural sociologists sometimes traffic in to justify anti-cognitive commitments (Wuthnow, 1989). When going "below" the individual, the cultural sociologist will not find atomized elements, but rather the repository of shared cognitive processes constitutive of "socially embodied" collective knowledge (Collins, 1993). These 
processes, in their turn, spill out into the world via bodily, interactive, and material scaffoldings for the realization of socio-cultural phenomena (Wilson, 2004a).

We close by returning to the issue of the implications of cognitive neuroscience for everyday practice in cultural analysis. As alluded to at the outset, we believe that the two fields have, at the moment, a "moderate" type of dependence. That means that conditional on questions or approach, some cultural sociologists-especially those seeing their work as closer to "humanistic" forms of inquiry traditionally defined-can carry out their work with either no or minimal engagement with cognitive neuroscience. Yet, note that even within the humanities, studies of literature, aesthetics, narrative, and history, are beginning to make contact with cognitive neuroscience, as given by emerging interfields such as the "neurohumanities."10

For other cultural sociologists the links are stronger and the dependencies are clearer (Cerulo, 2010). This is especially the case for cultural sociologists interested in the link between meaning, action, and experience (Lizardo and Strand, 2010), enculturation via skill acquisition (Pagis, 2010; Winchester, 2016), the link between language and cognition (Ignatow, 2007; Stoltz and Taylor, 2017), or the way that persons are coupled via intersubjective "entrainment" loops (Summers-Effler et al., 2014), among other topics. These analysts are increasingly unable to have the luxury to ignore developments in cognitive neuroscience as they speak to the core nature of the fundamental concepts used to interpret empirical materials and account for observed phenomena. Ignoring the cognitive scientific work would lead, as we noted at the outset, to analytic pitfalls, theoretical dead-ends, and misleading conclusions. This situation is likely to become more pressing as the boundaries between the fields become blurrier and the trafficking of concepts, theories, and tools at the interfield 
trading zone becomes more intense.

In this last respect, the nascent interfield that stands as a so far successful model of how the type of productive interchange we envision is that of neuroanthropology (Lende and Downey, 2012). ${ }^{11}$ This is a appossite model for cultural sociologists, because it is a merger between the ethnographic/cultural side of anthropology and cognitive neuroscience. Some of the leaders of the new field are qualitative anthropologists steeped in a similar "fieldwork culture" (e.g., Downey, 2014) as sociological ethnographers (Wacquant, 2015).

In spite of the existence of the relatively successful neuroanthropology merger, it is important to reiterate that cultural sociology is a more complex and multifaceted area and that we may be speaking of multiple lines of connection to cognitive neuroscience; some of which will be stronger, others weaker. For instance, it is clear that understanding the neural foundations of language has implications for the work of the growing number of cultural sociologists who use automated text analysis to capture meaning structures (Ignatow, 2015), but cognitive neuroscientific insights may be less important for those pursuing something closer to cultural history, narrative studies, or other forms of "textual" interpretations of action.

Nevertheless, insofar as these last do help themselves to substantive theories about the ways that symbols work, or the nature of meaning and language and their link to practices (Biernacki, 2000), then developments in cultural theory inspired by cognitive neuroscience will indirectly affect even the most humanistic strands of work. In this respect, an argument can be made that all branches of cultural analysis, irrespective of method or approach, will be affected by the neuroscientific turn-some more strongly than others. This is not a bad thing, since, as we noted at the outset, while not all cultural theorists or cultural sociologists need join the

\footnotetext{
${ }^{11}$ https://blogs.plos.org/neuroanthropology/
} 
cognitive-neuroscience fray, better cultural theory and better cultural analysis (and perhaps in the near future better cognitive neuroscience) would result from such engagement.

\section{Acknowledgements}

[optional]

\section{About the authors}

Please include short professional bios of 100 words or less here.

Omar Lizardo is the LeRoy Neiman Term Chair Professor in the Department of Sociology at the University of California, Los Angeles. His areas of research interest include the sociology of culture, social theory, social networks, the sociology of emotion, social stratification, cognitive social science, and organization theory. He is currently a member of the editorial advisory board of Social Forces, Theory and Society, Poetics, Sociological Forum, Journal for the Theory of Social Behaviour, and Journal of World-Systems Research and, with Rory McVeigh and Sarah Mustillo, he is one of the current co-editors of American Sociological Review.

Brandon Sepulvado is a $\mathrm{PhD}$ candidate in the Department of Sociology at the University of Notre Dame, where he is also affiliated with the Interdisciplinary Center for Network Science and Applications (iCeNSA). He specializes in computational social science, and his research has been supported by the U.S. government (through NSF and a Fulbright fellowship), the French government (through a Chateaubriand fellowship), the Nanovic Institute for European Studies, and the Countway Library of Medicine. His published work has appeared in such venues as Sociological Theory, American Sociologist and Journal for the Scientific 
Study of Religion.

Dustin S. Stoltz is a Ph.D. candidate in the Department of Sociology at the University of Notre Dame and a Doctoral Affiliate with the Kellogg Institute for International Studies. His primary field of inquiry is economic sociology, followed closely by cultural sociology, network analysis, organizational studies, computational social science, and cognitive social science. His published and forthcoming work is in Sociological Theory, Journal for the Theory of Social Behaviour, Socius, Poetics, The American Sociologist, and the European Journal of Social Theory.

Marshall A. Taylor is an Assistant Professor of Sociology at New Mexico State University. His areas of research interest include cultural and cognitive sociology, computational social science, and political sociology. His published work has appeared in such venues as Sociological Theory, Poetics, American Journal of Cultural Sociology, Socius, and the Stata Journal, among others. 


\section{References}

Alexander JC (1992a) Cultivating Differences: Symbolic Boundaries and the Making of Inequality. In: Lamont M and Fournier M (eds) Citizen and Enemy as Symbolic Classification: On the Polarizing Discourse of Civil Society. University of Chicago Press, pp. 289-308.

Alexander JC (1992b) The promise of a cultural sociology. Theory of culture. Berkeley: University of California Press: 293-323.

Alexander JC (2005) Why Cultural Sociology Is Not 'Idealist' A Reply to McLennan. Theory, Culture \& Society 22(6). Sage Publications London, Thousand Oaks and New Delhi: 19-29.

Alexander JC (2003) The Meanings of Social Life: A Cultural Sociology. Oxford University Press.

Alexander JC and Philip S (2001) The Strong Program in Cultural Theory: Elements of a Structural Hermeneutics. In: Handbooks of Sociological Theory. Springer, pp. 135-150.

Alexander JC, Giesen B, Münch R, et al. (eds) (1987) The Macro-Micro Link. Berkeley, CA: University of California Press.

Anderson ML (2014) After Phrenology: Neural Reuse and the Interactive Brain. MIT Press.

Armstrong EA and Crage SM (2006) Movements and Memory: The Making of the Stonewall Myth. American sociological review. 71(5): 724-751.

Barsalou LW (2003a) Abstraction in perceptual symbol systems. Philosophical transactions of the Royal Society of London. Series B, Biological sciences 358(1435): 1177-1187.

Barsalou LW (2003b) Situated simulation in the human conceptual system. Language and cognitive processes 18(5-6): 513-562.

Barsalou LW (2016) On Staying Grounded and Avoiding Quixotic Dead Ends. Psychonomic bulletin \& review 23(4). Springer: 1122-1142.

Becker H and Blanche G (1957) Participant Observation and Interviewing: A Comparison. Human organization 16(3): 28-32.

Berger PL and Luckmann T (1966) The Social Construction of Reality: A Treatise in the Sociology of Knowledge. Anchor books.

Biernacki R (2000) Language and the Shift from Signs to Practices in Cultural Inquiry. History and theory 39(3) : 289-310.

Black D (2000) Dreams of Pure Sociology. Sociological Theory 18(3): 343-367.

Bloch M (1991) Language, Anthropology and Cognitive Science. Man 26(2): 183-198.

Bloch M (2008) Why religion is nothing special but is central. Philosophical transactions of the Royal Society 
of London. Series B, Biological sciences 363(1499): 2055-2061.

Bloch M (2012) Anthropology and the Cognitive Challenge. Anthropology and the Cognitive Challenge. Cambridge University Press.

Bloch M (2015) In and Out of Each Other's Bodies: Theory of Mind, Evolution, Truth, and the Nature of the Social. Routledge.

Blouw P, Peter B, Eugene S, et al. (2015) Concepts as Semantic Pointers: A Framework and Computational Model. Cognitive science 40(5): 1128-1162.

Boudon R (2011) Une approche cognitive de la rationalité. Idées économiques et sociales 165(3): 24-36.

Bourdieu P (1990) The Logic of Practice. Stanford University Press.

Browne A and Sun R (1999) Connectionist variable binding. Expert Systems 16(3): 189-207.

Buchweitz A, Augusto B, Shinkareva SV, et al. (2012) Identifying bilingual semantic neural representations across languages. Brain and language 120(3): 282-289.

Casasanto D and Boroditsky L (2008) Time in the mind: using space to think about time. Cognition 106(2) : 579-593.

Cassirer E (1957) The Philosophy of Symbolic Forms. Volume III. Duke University Press.

Cerulo KA (2010) Mining the intersections of cognitive sociology and neuroscience. Poetics 38(2): $115-132$.

Chartrand TL and Bargh JA (1999) The chameleon effect: the perception-behavior link and social interaction. Journal of personality and social psychology 76(6): 893-910.

Cheng CM and Chartrand TL (2003) Self-monitoring without awareness: using mimicry as a nonconscious affiliation strategy. Journal of personality and social psychology 85(6): 1170-1179.

Clark A (1997) Being There: Putting Brain, Body, and World Together Again. MIT Press.

Cleeremans AACF (2003) The Unity of Consciousness: Binding, Integration, and Dissociation. Oxford University Press.

Clément F (2011) L'esprit de la sociologie: les sociolgues et le fonctionnement de l'esprit humain. In: Clément F and Kaufmann L (eds) La Sociologie Cognitive. Paris: Éditions de la Maison des Sciences de l'Homme, pp. 101-133.

Collins HM (1993) The Structure of Knowledge. Social research 60(1): 95-116.

Collins R (2004) Interaction Ritual Chains. Princeton University Press.

Crossley N (1995) Merleau-Ponty, the Elusive Body and Carnal Sociology. Body \& Society 1(1): 43-63.

Damasio AR (1994) Descartes' error: Emotion, rationality and the human brain. New York: Putnam. 
Damasio AR (1999) The Feeling of What Happens: Body and Emotion in the Making of Consciousness. Harvest book. Harcourt Brace.

De Grauwe S, Willems RM, Shirley-Ann R, et al. (2014) Embodied language in first- and second-language speakers: Neural correlates of processing motor verbs. Neuropsychologia 56: 334-349.

de Saussure F (1964) Course in General Linguistics. F, Bally C, and Sechehaye A (eds). Chicago: Open Court.

DiMaggio P (1997) Culture and Cognition. Annual review of sociology 23: 263-287.

DiTomaso N (1982) 'Sociological Reductionism’ From Parsons to Althusser: Linking Action and Structure in Social Theory. American sociological review: 14-28.

Douglas M (2002) Purity and Danger. New York: Routledge.

Downey G (2014) 'Habitus in Extremis': From Embodied Culture to Bio-Cultural Development. Body \& Society..

Dreyfus HL and Spinosa C (1999) Coping with Things-in-themselves: A Practice-Based Phenomenological Argument for Realism. Inquiry: a journal of medical care organization, provision and financing 42(1): 49-78.

Du Bois WEB (1897) Strivings of the Negro People. The Atlantic, 1 August. Available at: https://www.theatlantic.com/magazine/archive/1897/08/strivings-of-the-negro-people/30544 6/ (accessed 1 November 2018).

Durkheim E (1974) Individual and collective representations. In: Sociology and Philosophy. Free Press: New York.

Durkheim E (1982) Rules of Sociological Method. Lukes S (ed.). New York: The Free Press.

Duster T (2006) Comparative Perspectives and Competing Explanations: Taking on the Newly Configured Reductionist Challenge to Sociology. American sociological review 71(1): 1-15.

Edelman GM (1992) Bright Air, Brilliant Fire: On the Matter of the Mind. New York: Basic Books.

Eliasmith C (2013) How to Build a Brain. Oxford University Press.

Elliott, A (2019) Social Theory and Psychoanalysis in Transition. Routledge.

Emirbayer M and Mische A (1998) What is agency? American journal of sociology 103(4): 962-1023.

Engman A and Cranford C (2016) Habit and the Body: Lessons for Social Theories of Habit from the Experiences of People with Physical Disabilities. Sociological Theory 34(1): 27-44.

Evans V (2009) How Words Mean: Lexical Concepts, Cognitive Models, and Meaning Construction. OUP Oxford. 
Freud, S (1966) Project for a Scientific Psychology (1950 [1895]). Pp. 281-391 in The Standard Edition of the Complete Psychological Works of Sigmund Freud, Volume I (1886-1899): Pre-Psycho-Analytic Publications and Unpublished Drafts.

Feldman J (2013) The Neural Binding Problem(s). Cognitive neurodynamics 7(1): 1-11.

Ferrari PF and Vittorio G (2007) Mirror neurons and intersubjectivity. In: Advances in Consciousness Research, pp. 73-88.

Foster JG (2018) Culture and computation: Steps to a Probably Approximately Correct theory of culture. Poetics 68: 144-154.

Franks DD (2013) Why We Need Neurosociology as Well as Social Neuroscience. In: Franks DD and Turner JH (eds) Handbook of Neurosociology. pp. 27-32.

Gallese V (1998) Mirror neurons and the simulation theory of mind-reading. Trends in cognitive sciences 2(12): 493-501.

Gallese V and Lakoff G (2005) The Brain's concepts: the role of the Sensory-motor system in conceptual knowledge. Cognitive neuropsychology 22(3): 455-479.

Gallese V and Metzinger T (2003) Motor ontology: the representational reality of goals, actions and selves. Philosophical psychology 16(3): 365-388.

Garfinkel H (1967) Studies in Ethnomethodology. Prentice-Hall.

Geertz C (1973) The Interpretation of Cultures: Selected Essays. Basic Books.

Gentner D (1983) Structure-mapping: A theoretical framework for analogy. Cognitive science 7(2): $155-170$.

Giddens A (1979) Central Problems in Social Theory: Action, Structure, and Contradiction in Social Analysis. University of California Press.

Glenberg AM (1997) What memory is for: Creating meaning in the service of action. The Behavioral and brain sciences $20(01): 41-50$.

Glenberg AM and Kaschak MP (2002) Grounding language in action. Psychonomic bulletin \& review 9(3): 558-565.

Goldberg A and Stein SK (2017) Beyond'Social Contagion': Associational Diffusion and the Emergence of Cultural Variation.

Heiskala R (2011) The Meaning of Meaning in Sociology. The Achievements and Shortcomings of Alfred Schutz's Phenomenological Sociology. Journal for the theory of social behaviour 41(3): 231-246.

Hertz R (2013 [1960]) Death and the Right Hand. Routledge. 
Hertz R (2013) Death and the Right Hand. Routledge.

Hutchins E (1995) Cognition in the Wild. MIT Press.

Iacoboni M (2009) Imitation, empathy, and mirror neurons. Annual review of psychology 60: 653-670.

Ignatow G (2007) Theories of Embodied Knowledge: New Directions for Cultural and Cognitive Sociology? Journal for the theory of social behaviour 37(2): 115-135.

Ignatow G (2012) Mauss's lectures to psychologists: A case for holistic sociology. Journal of Classical Sociology 12(1): 3-21.

Ignatow G (2014) Ontology and method in cognitive sociology. Sociological Forum 29(4): 990-994.

Ignatow G (2015) Theoretical Foundations for Digital Text Analysis. Journal for the theory of social behaviour 46(1): 104-120.

Johnson M (2012) The Meaning of the Body: Aesthetics of Human Understanding. University of Chicago Press.

Johnson M and Lakoff G (2002) Why cognitive linguistics requires embodied realism. Cognitive Linguistics 13(3): 245-264.

Kaidesoja T (2013) Naturalizing Critical Realist Social Ontology. Taylor \& Francis.

Kaufmann L and Cordonier L (2011) Vers un naturalisme social. À la croisée des sciences sociales et des sciences cognitives. SociologieS.

Kovecses Z (2006) Language, Mind, and Culture: A Practical Introduction. Oxford University Press.

Kunda Z and Thagard P (1996) Forming impressions from stereotypes, traits, and behaviors: A parallel-constraint-satisfaction theory. Psychological review 103(2): 284.

Lakin JL, Jefferis VE, Cheng CM, et al. (2003) The chameleon effect as social glue: Evidence for the evolutionary significance of nonconscious mimicry. Journal of nonverbal behavior 27(3): 145-162.

Lakoff G (1993) The contemporary theory of metaphor. In: Ortony A (ed.) Metaphor and Thought. Cambridge University Press, pp. 202-251.

Lakoff G (2009) The Neural Theory of Metaphor. DOI: 10.2139/ssrn.1437794.

Lakoff G and Johnson M (1980) Conceptual Metaphor in Everyday Language. The journal of philosophy 77(8): 453-486.

Lakoff G and Johnson M (1999) Philosophy in the Flesh: The Embodied Mind and Its Challenge to Western Thought. New York: Basic Books.

Lamont M, Small ML, Harris D, et al. (2008) Culture matters. the role of culture in explaining poverty. In: David Harris AL (ed.) The Colors of Poverty: Why Racial and Ethnic Disparities Persist. New York, NY: Russell Sage Foundation, pp. 76-102. 
Lempert M (2014) Imitation. Annual review of anthropology 43(1): 379-395.

Lende DH and Downey G (2012) The Encultured Brain: An Introduction to Neuroanthropology. The MIT Press.

Levi-Strauss C (1966) The Savage Mind. Chicago: University of Chicago Press.

Lizardo O (2007) 'Mirror Neurons,' Collective Objects and the Problem of Transmission: Reconsidering Stephen Turner's Critique of Practice Theory. Journal for the theory of social behaviour 37(3): 319-350.

Lizardo O (2009a) Is a 'special psychology' of practice possible? From values and attitudes to embodied dispositions. Theory \& psychology 19 (6): 713-727.

Lizardo O (2009b) Taking Cognitive Dualism Seriously: Revisiting the Durkheim-Spencer Debate on the Rise of Individualism. Sociol. Perspect. 52(4): 533-555.

Lizardo O (2014) Beyond the Comtean Schema: The Sociology of Culture and Cognition Versus Cognitive Social Science. Sociological Forum 29(4): 983-989.

Lizardo O (2015) Culture, Cognition and Embodiment. In: International Encyclopedia of the Social \& Behavioral Sciences. Elsevier, pp. 576-581.

Lizardo O (2016a) Cultural Symbols and Cultural Power. Qualitative sociology 39(2): 199-204.

Lizardo O (2016b) Cultural theory. In: Abrutyn S (ed.) Handbook of Contemporary Sociological Theory. Switzerland: Springer, pp. 99-120.

Lizardo O and Strand M (2010) Skills, toolkits, contexts and institutions: Clarifying the relationship between different approaches to cognition in cultural sociology. Poetics 38(2): 205-228.

Lizardo O, Mowry R, Sepulvado B, et al. (2016) What Are Dual Process Models? Implications for Cultural Analysis in Sociology. Sociological Theory. 34(4): 287-310.

Lukes S (2003) The grand dichotomy of the twentieth century. In: Terence Ball And (ed.) The Cambridge History of Twentieth Century Though. Cambridge University Press, pp. 602-626.

Machamer P and Sytsma J (2007) Neuroscience and Theoretical Psychology: What's to Worry About? Theory \& psychology 17(2): 199-216.

Marcuse, H (2012) Eros and Civilization. Routledge.

Martin A (2007) The representation of object concepts in the brain. Annual review of psychology 58: $25-45$.

Martin JL (2010) Life's a beach but you're an ant, and other unwelcome news for the sociology of culture. Poetics 38(2): 229-244.

McCauley RN and Bechtel W (2001) Explanatory Pluralism and Heuristic Identity Theory. Theory \& 
psychology 11(6): 736-760.

Mead GH (1922) A Behavioristic Account of the Significant Symbol. The journal of philosophy 19(6): $157-163$.

Mears A (2014) Seeing culture through the eye of the beholder: four methods in pursuit of taste. Theory and society 43(3-4): 291-309.

Mellor PA and Shilling C (2010) Body pedagogics and the religious habitus: A new direction for the sociological study of religion. Religion 40(1): 27-38.

Meloni M (2014) Biology without Biologism: Social Theory in a Postgenomic Age. Sociology 48(4): $731-746$.

Merleau-Ponty M (1962) Phenomenology of Perception. Psychology Press.

Merleau-Ponty M (1968) The Visible and the Invisible. Northwestern University Press.

Michaelian K (2011) Is memory a natural kind? Memory Studies 4(2): 170-189.

Molnar-Szakacs I, Istvan M-S, Wu AD, et al. (2007) Do You See What I Mean? Corticospinal Excitability During Observation of Culture-Specific Gestures. PloS one 2(7): e626.

Mukerji C (2014) The cultural power of tacit knowledge: Inarticulacy and Bourdieu's habitus. American Journal of Cultural Sociology 2(3): 348-375.

Pagis M (2010) From Abstract Concepts to Experiential Knowledge: Embodying Enlightenment in a Meditation Center. Qualitative sociology 33(4): 469-489.

Parsons T (1937) The Structure of Social Action. New York: Free Press.

Parsons, T (1964) Social Structure and Personality. New York: Free Press.

Parsons T (1938) The Role of Ideas in Social Action. American sociological review 3(5): 652-664.

Parsons T (1991) The Early Essays. University of Chicago Press.

Patterson O (2014) Making Sense of Culture. Annual review of sociology 40(1): 1-30.

Peirce CS (1974) Collected Papers of Charles Sanders Peirce. Harvard University Press.

Pitts-Taylor V (2003) In the Flesh: The Cultural Politics of Body Modification. Springer.

Pitts-Taylor V (2014) Cautionary Notes on Navigating the Neurocognitive Turn. Sociological Forum 29(4): 995-1000.

Pitts-Taylor V (2015) A Feminist Carnal Sociology?: Embodiment in Sociology, Feminism, and Naturalized Philosophy. Qualitative sociology 38(1): 19-25.

Potter D, Mashburn A and Grissmer D (2013) The family, neuroscience, and academic skills: An interdisciplinary account of social class gaps in children's test scores. Social science research 42(2): 
$446-464$.

Pribram, K H and Gill M (1976) Freud's Project Reassessed. Hutchinson Radius.

Quilley S, Schröder T and Thagard P (2013) A complex systems approach to the study of ideology: Cognitive-affective structures and the dynamics of belief systems. Journal of social and political psychology. 1(1):337-363.

Reed IA (2013) Power: Relational, Discursive, and Performative Dimensions. Sociological Theory 31(3): 193-218.

Ricoeur P (1973) The Model of the Text: Meaningful Action Considered as a Text. Social research 38(3): 529-562.

Ridgeway C (1991) The Social Construction of Status Value: Gender and Other Nominal Characteristics. Social forces; a scientific medium of social study and interpretation 70(2). Oxford University Press: 367-386.

Rizzolatti G, Camarda R, Fogassi L, et al. (1988) Functional organization of inferior area 6 in the macaque monkey. Experimental brain research. Experimentelle Hirnforschung. Experimentation cerebrale 71(3): 491-507.

Robinson DT, Smith-Lovin L and Wisecup AK (2006) Affect Control Theory. In: Stets JE and Turner JH (eds) Handbook of the Sociology of Emotions. Handbooks of Sociology and Social Research. Springer US, pp. 179-202.

Russell B (1905) On denoting. Mind; a quarterly review of psychology and philosopby 14(56): 479-493.

Ryle G (2002[1949]) The Concept of Mind. Chicago: The University of Chicago Press.

Ryle G (1971) The thinking of thoughts: What is 'le Penseur' Doing? In: Collected Papers. London: Hutchinson \& Co.

Sakreida K, Katrin S, Claudia S, et al. (2013) Are abstract action words embodied? An fMRI investigation at the interface between language and motor cognition. Frontiers in buman neuroscience 7.

Sawyer RK (2002) Durkheim's Dilemma: Toward a Sociology of Emergence. Sociological Theory 20(2): $227-247$.

Schubert TW (2005) Your highness: vertical positions as perceptual symbols of power. Journal of personality and social psychology 89(1): 1-21.

Schutz A (1962) Collected Papers. Springer Netherlands.

Schwartz B (1981) Vertical Classification: A Study in Structuralism and the Sociology of Knowledge. University of Chicago Press.

Sepulvado B and Lizardo O (2017) Cognitive Sociology in France. The American sociologist 48(3): 
$366-381$.

Sewell WH Jr (2005) Logics of History: Social Theory and Social Transformation. University of Chicago Press.

Shastri L (1996) Temporal synchrony, dynamic bindings, and SHRUTI: A representational but nonclassical model of reflexive reasoning. The Behavioral and brain sciences 19(2): 331-337.

Shepherd H (2011) The Cultural Context of Cognition: What the Implicit Association Test Tells Us About How Culture Works. Sociological Forum 26(1): 121-143.

Shore B (1996) Culture in Mind: Cognition, Culture, and the Problem of Meaning. Oxford University Press.

Shotter J (1993) Conversational Realities: Constructing Life Through Language. SAGE.

Smelser, N J (1999). The Social Edges of Psychoanalysis. University of California Press.

Sørensen J (2007) A Cognitive Theory of Magic. Cognitive science of religion series. Rowman \& Littlefield Pub Incorporated.

Sperber D (1996) Explaining Culture: A Naturalistic Approach. Wiley.

Sperber D (1997) Individualisme méthodologique et cognitivisme. In: Raymond Boudon, Alban Bouvier, and François Chazel (ed.) Cognition et Sciences Sociales: La Dimension Cognitive Dans L'analyse Sociologique. Paris: Presses universitaires de France., pp. 123-136.

Squire LR (2004) Memory systems of the brain: a brief history and current perspective. Neurobiology of learning and memory 82(3): 171-177.

Srivastava SB and Banaji MR (2011) Culture, Cognition, and Collaborative Networks in Organizations. American sociological review 76(2): 207-233.

Steele CM (2011) Whistling Vivaldi: How Stereotypes Affect Us and What We Can Do. W. W. Norton.

Stoltz DS (2018) Relations and Relationships: Clarifying the Terms of the 'New' Relational Economic Sociology. The American Sociologist 49(1): 64-79.

Stoltz DS and Lizardo O (2018) Deliberate Trust and Intuitive Faith: A Dual-Process Model of Reliance. Journal for the Theory of Social Behaviour 48(2): 230-250.

Stoltz DS and Taylor MA (2017) Paying with Change: The Purposeful Enunciation of Material Culture. Poetics 62: 26-39.

Strand M and Lizardo O (2015) Beyond World Images: Belief as Embodied Action in the World. Sociological Theory 33(1): 44-70.

Strauss C and Quinn N (1997) A Cognitive Theory of Cultural Meaning. Cambridge University Press.

Suddendorf T (2013) Mental time travel: continuities and discontinuities. Trends in cognitive sciences 17(4): 151-152. 
Summers-Effler E (2004) A Theory of the Self, Emotion, and Culture. In: Turner JH (ed.) Theory and Research on Human Emotions. Advances in Group Processes. Emerald, pp. 273-308.

Summers-Effler E, Van Ness J and Hausmann C (2014) Peeking in the Black Box Studying, Theorizing, and Representing the Micro-Foundations of Day-to-Day Interactions. Journal of Contemporary 44 (4). jce.sagepub.com: 450-479.

Taylor MA, Stoltz DS and McDonnell TE (2019) Binding Significance to Form: Cultural Objects, Neural Binding, and Cultural Change. Poetics 73:1-16.

Tavory I and Eliasoph N (2013) Coordinating Futures: Toward a Theory of Anticipation. The American journal of sociology 118(4): 908-942.

Thagard P (2008a) Hot Thought: Mechanisms and Applications of Emotional Cognition. MIT press.

Thagard P (2008b) How cognition meets emotion: Beliefs, desires, and feelings as neural activity. In: Kuenzle D, Brun G, and Doguoglu U (eds) Epistemology and Emotions. Aldershot, UK: Ashgate, pp. 167-184.

Thagard P and Stewart TC (2011) The AHA! Experience: Creativity Through Emergent Binding in Neural Networks. Cognitive science 35(1): 1-33.

Todes S (2001) Body and World. Cambridge, MA: MIT Press.

Tomasello M (1999) The Human Adaptation for Culture. Annual review of anthropology 28(1): 509-529.

Turner SP (2001) Throwing out the tacit rule book: Learning and practices. In: Schatzki TR, Cetina KK, and von Savigny E (eds) The Practice Turn in Contemporary Theory. New York: Routledge, pp. 129-139.

Turner SP (2007) Social Theory as a Cognitive Neuroscience. European Journal of Social Theory 10(3): $357-374$.

Turner SP and Factor RA (1994) Max Weber: The Lanyer as Social Thinker. Taylor \& Francis.

Vaisey S (2009) Motivation and Justification: A Dual-Process Model of Culture in Action. The American journal of sociology 114(6): 1675-1715.

van der Velde F and de Kamps M (2006) Neural blackboard architectures of combinatorial structures in cognition. Behavioral and Brain Sciences 29(1): 37-70.

Veblen T (1898) The instinct of workmanship and the irksomeness of labor. The American journal of sociology 4(2): 187-201.

von der Malsburg C (1994) The Correlation Theory of Brain Function. In: van Hemmen and Klaus Schulten EDJL (ed.) Models of Neural Networks. Springer, pp. 95-119.

Wacquant LJD (2015) For a sociology of flesh and blood. Qualitative sociology 38(1): 1-11. 
Wacquant LJD (2004) Body \& Soul: Notebooks of an Apprentice Boxer. Oxford University Press.

Wagner-Pacifici R and Schwartz B (1991) The Vietnam Veterans Memorial: Commemorating a Difficult Past. The American journal of sociology 97(2). University of Chicago Press: 376-420.

Wan PY (2011) Reframing the Social: Emergentist Systemism and Social Theory. Ashgate.

Whitehouse H (2004) Modes of Religiosity: A Cognitive Theory of Religious Transmission. Cognitive science of religion series. New York: AltaMira Press.

Wierzbicka A (1996) Semantics: Primes and Universals. Oxford University Press, UK.

Willems RM and Hagoort P (2007) Neural evidence for the interplay between language, gesture, and action: A review. Brain and language 101(3): 278-289.

Willis PE (1978) Profane Culture. Routledge \& K. Paul.

Wilson RA (2004a) Boundaries of the Mind: The Individual in the Fragile Sciences-Cognition. Cambridge University Press.

Wilson RA (2004b) Realization: Metaphysics, Mind, and Science. Pbilosophy of science 71(5): 985-996.

Winchester D (2016) A Hunger for God: Embodied Metaphor as Cultural Cognition in Action. Social forces; a scientific medium of social study and interpretation 95(2). Oxford University Press: 585-606.

Winch P (2012) The Idea of a Social Science and Its Relation to Philosophy. Routledge.

Wood ML, Stoltz DS, Van Ness J, Taylor MA (2018) Schemas and Frames. Sociological Theory 36(3): 244-261.

Wuthnow R (1989) Meaning and Moral Order: Explorations in Cultural Analysis. University of California Press. 